\title{
Use of World Health Organization Indicators to Assess Pharmaceutical Assistance in Primary Health Care: An Integrative Review
}

\author{
Sandra da Silva Guimarães ${ }^{1 *}$, André Santos da Silva², Ana Paula Soares Gondim \\ 'Department of Pharmaceutical Sciences, Doctoral Student in Pharmaceutical Sciences, Federal University of Ceará, Fortaleza, Ceará, BRAZIL. \\ ${ }^{2}$ College of Pharmaceutical Sciences, Federal University of Sao Francisco Valley, Pernambuco, Petrolina, BRAZIL.
}

\begin{abstract}
Objective: Synthesize evidence related to the use of World Health Organization indicators to assess Pharmaceutical Assistance in Primary Health Care. Methods: The integrative review type research was carried out from 2008 to 2018. The Web of Science, Scopus, LILACS, MEDLINE via PubMed, Virtual Scielo Library, Virtual Health Library databases were used, using the keywords " Pharmaceutical Assistance ",' Primary Health Care "and" World Health Organization Indicators "in Portuguese, Spanish and English. Results: 1,102 publications were identified. 21 publications were selected that met the inclusion criteria. The most used indicators were those of prescription, present in 20 publications (95.2\%), followed by assistance indicators, in eight (38.1\%), indicators on the service, in seven (33.3\%). The research design was prospective in three (14\%) publications, retrospective in eight $(38 \%)$, retrospective / prospective in one $(5 \%)$ and the design was not cited in nine $(43 \%)$. All studies were above the recommended value $(<2)$ for the number of drugs prescribed per prescription and the percentage of drugs prescribed by the generic name, which must be $100 \%$ according to the recommended by the World Health Organization. Conclusion: It
\end{abstract}

was observed that the group of indicators of rational use of medicines was the most used, overlapping the other indicators of the World Health Organization (access and quality), applied for monitoring and evaluation in the pharmaceutical sector. In general, the indicators used in the studies included in the review did not show satisfactory results in comparison with the values established by the World Health Organization.

Key words: Evaluation, Drug Policies, Rational use of Medication, Health Status Indicators, Pharmaceutical Services, National Policy of Pharmaceutical Assistance.

Correspondence

Ms. Sandra Da Silva Guimarães,

Department of Pharmaceutical Sciences, Doctoral Student in Pharmaceutical Sciences, Federal University of Ceará, Fortaleza, Ceará, BRAZIL.

Phone: +55-86-999993981

Email: ssfarmac@yahoo.com.br

DOI: 10.5530/jyp.2020.12.22

\section{INTRODUCTION}

Monitoring and evaluation of Pharmaceutical Assistance in countries is important to verify compliance with the objectives determined by the drug policies established for this sector. Even though there are countryspecific organizational differences, these objectives essentially involve three lines: access to essential medicines, availability of safe, effective and good quality medicines and the correct use of these medicines. ${ }^{1}$

The use of indicators helps the assessment and monitoring of work processes and their impacts with regard to the provision of information, obtained in a systematic way, making it possible to bring up important issues for the discussion and improvement of these activities. The use of indicators in Pharmaceutical Assistance impacts on the public health of the population that needs to have access to effective and quality medication and also have the knowledge to know how to use it safely. The irrational use of medicines has caused health problems to the population in several countries. Despite the importance of the medication to support health actions in an integral way, the population idealizes the medication as a consumer good, a fact that can increase the risks if the important criteria for rationality in its use are not obeyed. In addition, about a third of the world population does not have access to essential medicines, which implies serious morbidity and mortality, especially for childhood infections and chronic diseases.

In 1993, the World Health Organization, concerned with irrational practices involving the use of medicines, developed a set of indicators, in collaboration with the International Network for the Rational Use of Drugs in order to assess the performance of health services in three major areas that involve the use of medicines in Primary Health Care: prescription area, patient care area and health service area. ${ }^{2}$

As other factors that involve the use of medicines are necessary for the population to have access to quality medicines, in addition to their rational use, In 2007, the World Health Organization launched a set of indicators for the assessment and monitoring of the pharmaceutical situation in countries with the aim of monitoring the strategies adopted based on the national drug policies of each country. They are: access, quality and prescription indicators, in which they are broken down into prescription, assistance and service. ${ }^{1}$

Access indicators include purchasing capacity and availability of medicines, quality indicators include the quality of some processes, as well as the verification of care related to the preservation of the integrity of the drugs and the prescription indicators include issues related to the prescription, the information received by users and the organizational aspects.

This indicator package is organized into three groups which are organized hierarchically in Level I (process indicators), Level II (result / impact indicators) and Level III (in-depth evaluations of specific components of the pharmaceutical sector). This methodology makes it possible to monitor the progress of the strategies implemented based on the policies, as well as to compare the real situations in different, facilities, districts and countries. The motivation for this evaluation strategy was based on the need to obtain indicators that were used for the pharmaceutical 
sector and that evaluated the access and rational use of medicines due to their complexity and the transversal factors that influence this sector. As primary care is the user's first contact with the health care network, the World Health Organization uses these indicators in order to contribute so that the medication can be an important tool in comprehensive care. The World Health Organization provides, through these indicators, subsidies for the access and use of the medication to be evaluated and monitored, thus avoiding disorders resulting from its lack or its inappropriate use. ${ }^{1,3}$

Several published works show that the indicators are used as tools to evaluate Pharmaceutical Assistance in Primary Health Care, however, there are still limitations on its use, the group of indicators related to the rational use of medicines being the most used. In addition, the use of these indicators is mostly performed by developing countries. ${ }^{4-15}$

In this context, this study presents an integrative review that covers information on the use of indicators for the monitoring and evaluation of Pharmaceutical Assistance in Primary Health Care in several countries, generating a critical analysis regarding the results found against the standards established by the World Health Organization. The objective of this integrative review, based on the PRISMA recommendation to synthesize evidence, was to analyze articles published in the last ten years and substantiate the evidence related to Pharmaceutical Care, using the World Health Organization's indicators in the context of Primary Health Care. ${ }^{16}$

\section{MATERIALS AND METHODS}

The integrative literature review was guided by the Preferred Reporting Items for Systematic Reviews and Meta-Analyzes guide. ${ }^{16}$ The search, limited to electronic bases, without manual search in other sources. The databases, Web of Science, LILACS, Scopus, MEDLINE via PubMed,
Virtual Library Scielo, Virtual Health Library, were consulted during the month of May 2019, using the descriptors in the languages: Portuguese, Spanish and English combined with Boolean operators: ("Organização Mundial da Saúde" OR "Organización Mundial de la Salud" OR "World Health Organization" OR "OMS" OR "WHO”) AND ("Indicadores" OR "Indicators") AND ("AtençãoPrimária à Saúde" OR "Atención Primaria de Salud"OR "Primary Health Care"). These terms were selected from the structured vocabulary of Health Sciences Descriptors (DeCS) (http:// decs.bvs.br/), created by BIREME and developed from Medical Subject Headings (MeSH), of the U.S. National Library of Medicine.

The titles and abstracts of the articles identified by the initial search strategy were independently assessed by two authors (S.S.G. and A.S.S.), following the inclusion and exclusion criteria. Duplicate studies were removed and differences were resolved by consensus. When the title or abstract did not clearly indicate whether an article should be selected, the full text was obtained and read for inclusion according to predetermined criteria. The articles considered relevant in the first screening were retrieved and selected for eligibility. There was no manual search in the references of selected articles.

The inclusion and exclusion criteria were defined based on the guiding question of this study: to analyze, using World Health Organization indicators, whether Pharmaceutical Assistance has been showing positive results and integrated with the service in Primary Health Care.

Thus, the inclusion criteria were: to be a complete original article (with full text available), written in Portuguese, Spanish or English on the studies developed in the Primary Health Care service; having a target population without particular age, gender or health condition; use at least one of the three sets of indicators of drug use developed by the World Health Organization; and have been published from 2008 to 2018. The following were excluded from the integrative review: review articles, abstracts,

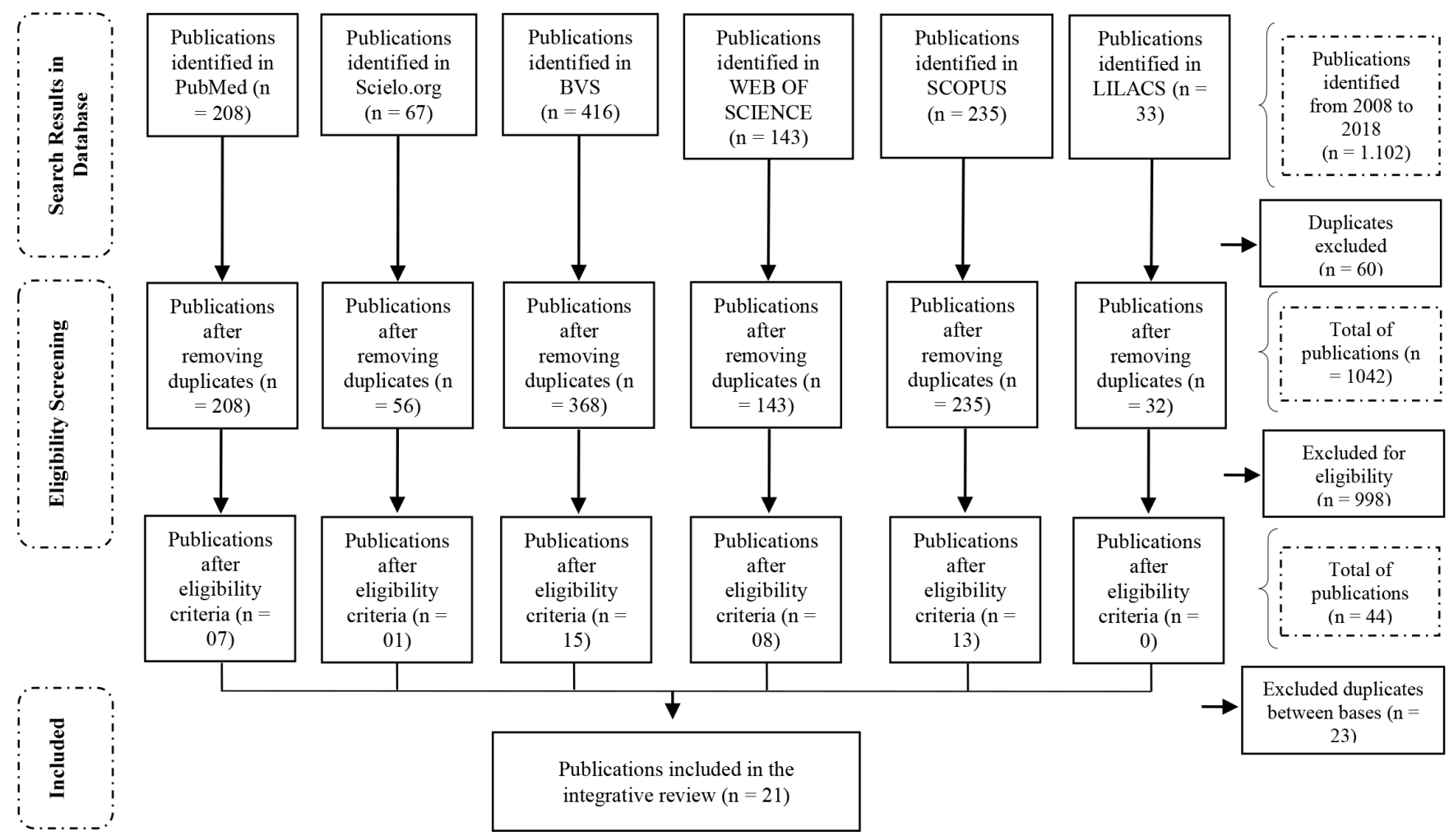

Figure 1: Identification and selection of articles for integrative review on the use of WHO indicators for the evaluation of Pharmaceutical Assistance in primary health care, 2008 to 2018. 
Table 1: Characteristics of publications included in the integrative review on the use of WHO indicators for the evaluation of Pharmaceutical Assistance in primary health care, 2008 to 2018.

\begin{tabular}{|c|c|c|c|}
\hline Author ${ }^{a}$ & Year $^{b}$ & Country ${ }^{c}$ & Design $^{d}$ \\
\hline Adisa et al. & 2015 & Nigeria & Prospective cross-sectional \\
\hline Ahiabu et al. & 2016 & Ghana & Prospective cross-sectional \\
\hline $\begin{array}{l}\text { Ahmadi and } \\
\text { Zarei }\end{array}$ & 2017 & Iran & Prospective cross-sectional \\
\hline $\begin{array}{l}\text { Ahmed and } \\
\text { Islam }\end{array}$ & 2012 & Bangladesh & Cross-sectional \\
\hline Akl et al. & 2014 & Egypt & Retrospective cross-sectional \\
\hline Atif et al. & 2016 & Pakistan & $\begin{array}{c}\text { Descriptive, non-experimental and } \\
\text { cross-sectional. }\end{array}$ \\
\hline $\begin{array}{l}\text { Awad and } \\
\text { Al-Saffar }\end{array}$ & 2010 & Kuwait & $\begin{array}{c}\text { Descriptive, quantitative, } \\
\text { comparative and cross-sectional } \\
\text { prospective. }\end{array}$ \\
\hline Ayoub et al. & 2017 & Palestine & Retrospectivo \\
\hline Coradi et al. & 2017 & Brazil & Cross-sectional Descriptive \\
\hline Costa et al. & 2008 & India & Cross-sectional \\
\hline Dong et al. & 2010 & China & Cross-sectional \\
\hline Dutra et al. & 2016 & Brazil & $\begin{array}{l}\text { Retrospective and prospective } \\
\text { cross-sectional. }\end{array}$ \\
\hline Enato et al. & 2012 & Nigeria & Cross-sectional \\
\hline Lima et al. & 2017 & Brazil & Cross-sectional \\
\hline Manbile et al. & 2016 & Tanzania & Cross-sectional Descriptive \\
\hline Mashalla et al. & 2017 & Botswana & $\begin{array}{l}\text { Cross-sectional / Retrospective / } \\
\text { Descriptive and Non-experimental }\end{array}$ \\
\hline Menolli et al. & 2009 & Brazil & $\begin{array}{c}\text { Cross-sectional / descriptive, and } \\
\text { not controlled. }\end{array}$ \\
\hline Parveen et al. & 2016 & India & Prospective cross-sectional \\
\hline Sarwar et al. & 2018 & Paquistan & $\begin{array}{c}\text { Cross-sectional and retrospective } \\
\text { observational. }\end{array}$ \\
\hline Song et al. & 2014 & China & Retrospective cross-sectional \\
\hline $\begin{array}{c}\text { Yousif and } \\
\text { Supakankunti }\end{array}$ & 2016 & Sudan & Retrospective cross-sectional \\
\hline
\end{tabular}

${ }^{\mathrm{a}}$ Main author; ${ }^{\mathrm{b}}$ Year of publication; ${ }^{\mathrm{c} C o u n t r y}$ of origin of the studies ${ }^{\mathrm{d}}$ Experimental design of the study.

theses and other monographs; studies developed exclusively in tertiary health care services (including hospitals); studies with a specific population, as well as instrument validations; studies that used other methods for the evaluation of Pharmaceutical Assistance that are not included in the set of indicators of the World Health Organization / International Network for the Rational use of Drugs; studies that did not provide enough details in their methodologies and results to answer the question of this study.

In the case of studies that obtained results at different levels of health care, only the results related to Primary Health Care were considered. For the articles that presented results of indicators in different locations or regions, the averages of these values were verified and used.

The review data was extracted and summarized with the following information: name of the first author, year of publication, country, study location, duration, objective, design, type of sampling, sample number, indicators used and conclusions. The data extraction procedure was performed by two authors (A.S.S. and S.S.G) independently and the differences were resolved by consensus.

The review study treated the results of the indicators obtained in the articles with the same importance, without taking into account the sample size and variance. The indicators used for the evaluation of Pharmaceutical Assistance were identified and their results were analyzed through their comparisons with the reference values recommended by the World Health Organization and checked for adequacy.

\section{RESULTS}

In the review, 1,102 publications were identified considering the six electronic bases used to search for information about the research objectWeb of Science, Scopus, LILACS, MEDLINE via PubMed, Virtual Scielo Library and Virtual Health Library. Among the publications found, 60 were excluded due to duplication within each electronic database, with 1,042 publications remaining for analysis and eligibility, according to the inclusion and exclusion criteria. During the process of eligibility of publications, 998 publications were removed because they were outside the pre-established criteria. After all the careful analysis, 44 publications were elected; however, 23 of them were excluded because they had duplicates between the databases. Thus, 21 publications were selected that met the inclusion criteria (Figure 1).

By following the indicators developed and recommended by the World Health Organization / International Network for the Rational Use of Drugs with the objective of measuring performance in three areas related to the rational use of medicines, the most used were prescription drugs, which were present in 20 publications (95.2\%), followed by assistance indicators with eight (38.1\%) and service indicators with seven (33.3\%). Regarding the geographical distribution of publications included in the survey, four (19\%) came from South American countries (exclusively from Brazil), seven (33\%) from Africa (Botswana, Egypt, Ghana, Nigeria, Sudan and Tanzania) and ten (48\%) from Asia (Bangladesh, China, India, Iran, Kuwait, Palestine and Pakistan). The design was prospective in three (14\%), retrospective in eight (38\%), retrospective / prospective in one (5\%) and the design was not cited in nine (43\%). The publications selected according to the established criteria were mostly concentrated between the years 2016 and 2017, in which the search results showed six $(28.6 \%)$ and five $(23.8 \%)$ respectively, for those years. The remaining publications were distributed as follows: two (9.5\%) in 2010 and two (9.5\%) in 2012 and one per year, in the remaining years $(2008,2009$, 2003, 2014, 2015 and 2018), which represented 4.8\% for each year identified (Figure 1).

In the studies that used and presented the results of the prescription, assistance and service indicators, the following results were found, as shown in Tables 2, 3: all studies were above the recommended value $(<2)$ for the number of drugs prescribed per prescription, as well as, in the percentage of drugs prescribed by the generic name that must be $100 \%$ according to the recommended by the World Health Organization. The percentage of antibiotics prescribed is in line with the literature $(<30)$ in only $19 \%$ of the studies and the percentage of injectable drugs in $64.7 \%$. The average consultation time in all studies was less than $15 \mathrm{~min}$ and the average dispensing time were less than $180 \mathrm{sec}$, both indicators showing compliance with the literature. For the indicator that measures the percentage of properly labeled drugs, only one study shows compliance with the literature and for the indicator percentage of users who know how to use the correct dose, there was no study in accordance with the literature. Regarding the availability of copies of the Local Drug List, only one study was in compliance with the literature and in relation to the availability of key drugs, no study was in compliance with the literature. 
Figure 2: Summary of the results of the integrative review on the use of WHO indicators for the evaluation of Pharmaceutical Assistance in primary health care, studies from 2008 to 2015.

\begin{tabular}{|c|c|c|c|c|c|c|c|c|c|c|}
\hline \multicolumn{11}{|c|}{ 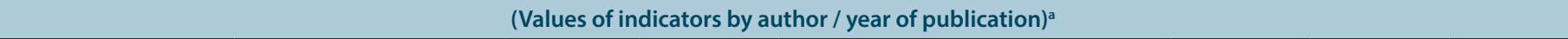 } \\
\hline Indicators ${ }^{b}$ & $\begin{array}{l}\text { Costa et al. } \\
\quad(2008)\end{array}$ & $\begin{array}{l}\text { Menolli et } \\
\text { al. (2009) }\end{array}$ & $\begin{array}{l}\text { Dong et } \\
\text { al. (2010) }\end{array}$ & $\begin{array}{l}\text { Awad and } \\
\text { Al-Saffar } \\
(2010)\end{array}$ & $\begin{array}{l}\text { Ahmed } \\
\text { and Islam } \\
(2012)\end{array}$ & $\begin{array}{l}\text { Enato et al. } \\
\quad(2012)\end{array}$ & $\begin{array}{l}\text { Akl et al. } \\
\text { (2013) }\end{array}$ & $\begin{array}{l}\text { Song et al. } \\
\text { (2014) }\end{array}$ & $\begin{array}{l}\text { Adis et al. } \\
\text { (2015) }\end{array}$ & $\begin{array}{l}\text { Reference } \\
\text { values }\end{array}$ \\
\hline \multicolumn{11}{|l|}{ Prescription } \\
\hline $\begin{array}{l}\text { Average number of } \\
\text { drugs prescribed per } \\
\text { consultation }\end{array}$ & 2.8 & 2.2 & 2.4 & 2.9 & 2.3 & 5.7 & 2.5 & 3.5 & 5.8 & $<2^{c}$ \\
\hline$\%$ generic & 48.4 & 66.5 & 64.1 & 17.7 & 0.0 & 50.2 & 95.4 & Absent & 68.0 & $100^{c}$ \\
\hline$\%$ antibiotics & 63.5 & 28.6 & 48.4 & 39.1 & 43.8 & 70.8 & 39.2 & 59.4 & 55.0 & $<30^{c}$ \\
\hline$\%$ injectables & 13.6 & 10.9 & 22.9 & 9.1 & Absent & 73.6 & 9.9 & 41.5 & 52.5 & $<20^{c}$ \\
\hline $\begin{array}{l}\% \text { prescription drugs } \\
\text { from the local or } \\
\text { national list }\end{array}$ & 66.9 & 73.3 & 67.7 & Absent & 64.5 & 59.8 & 95.4 & 71.6 & 99.1 & $100^{c}$ \\
\hline \multicolumn{11}{|l|}{ Assistences } \\
\hline $\begin{array}{l}\text { Average consultation } \\
\text { time (min) }\end{array}$ & 1.96 & 8.6 & - & 2.8 & 3.8 & - & 7.1 & - & - & $\geq 15^{\mathrm{d}}$ \\
\hline $\begin{array}{c}\text { Average dispensing } \\
\text { time (s) }\end{array}$ & 54.3 & Absent & - & 54.6 & 90 & - & 47.4 & - & - & $\geq 180^{\mathrm{d}}$ \\
\hline $\begin{array}{l}\% \text { of dispensed } \\
\text { medicines }\end{array}$ & 74.9 & 71.1 & - & 97.9 & 60.1 & - & 95.5 & - & - & $100^{c}$ \\
\hline $\begin{array}{c}\% \text { of properly labeled } \\
\text { drugs }\end{array}$ & 40.9 & Absent & - & 66.9 & 54.2 & - & 0 & - & - & $100^{c}$ \\
\hline $\begin{array}{l}\% \text { of users who know } \\
\text { how to use the correct } \\
\text { dose }\end{array}$ & 87.1 & Absent & - & 27.6 & 74.5 & - & 94 & - & - & $100^{c}$ \\
\hline \multicolumn{11}{|l|}{ Service } \\
\hline $\begin{array}{l}\% \text { availability of copies } \\
\text { of the LLME }\end{array}$ & 0 & - & - & - & 51.0 & - & 80 & - & - & $100^{c}$ \\
\hline $\begin{array}{c}\% \text { availability of key } \\
\text { drugs }\end{array}$ & 17.4 & - & - & - & 10.5 & - & 78.3 & - & - & $100^{c}$ \\
\hline
\end{tabular}

${ }^{a}$ Values of the indicators found in the integrative review by author/year of publication.

${ }^{b}$ WHO indicators for the evaluation of pharmaceutical assistance in Primary Health Care.

${ }^{c, d}$ Reference Values recommended by WHO ${ }^{c-34-35}$ - $-\mathrm{d}-36$

"-"it means that the author did not use the group of indicators. "Absent" means that the author did not present a result, although it has used the group of indicators from one of the three areas.

\section{DISCUSSION}

When meeting the criteria previously established for the review, 21 studies was included that used the indicators developed and recommended by the World Health Organization / International Network for the Rational use of Drugs in order to measure the performance of Pharmaceutical Assistance. Among the indicators used to evaluate Pharmaceutical Assistance, the group of indicators related to the rational use of medicines was found in the publications in their entirety. The most used within this group were the prescription indicators, which were present in 20 publications $(95.2 \%)$, followed by the assistance indicators in eight (38.1\%) and the service indicators with seven (33.3\%). The use of other access indicators and quality indicators for the selected publications was not observed, except in one of the publications, which used the group of access indicators (indicator of availability of medicines and geographical access to health units), in addition to indicators of rational drug use.
All included studies used the drug use indicators that were developed to be used as performance measures in the three general areas related to the rational use of drugs in primary care. This result may be related to the ease of application and the fact that these indicators are highly standardized and still do not need national adaptation for use in different countries. Another important point is that these indicators provide a simple, fast and reliable tool to assess the critical aspects of the use of medicines in Primary Health Care. The information obtained through these indicators can support strategies for monitoring and improving Pharmaceutical Care, this fact, which makes them quite viable. However, one of its weaknesses would be the failure to measure all the important aspects of medication use; this requires more intensive methodologies and more comprehensive and varied data sources. Only one of the selected studies ${ }^{9}$ it addresses other indicators that measure the availability of medicines and geographical access in primary health care units, in addition to the indicators of rational use of medicines. In this study, the availability of essential drugs varied from $100 \%$ to $60 \%$ between the time of the visit 


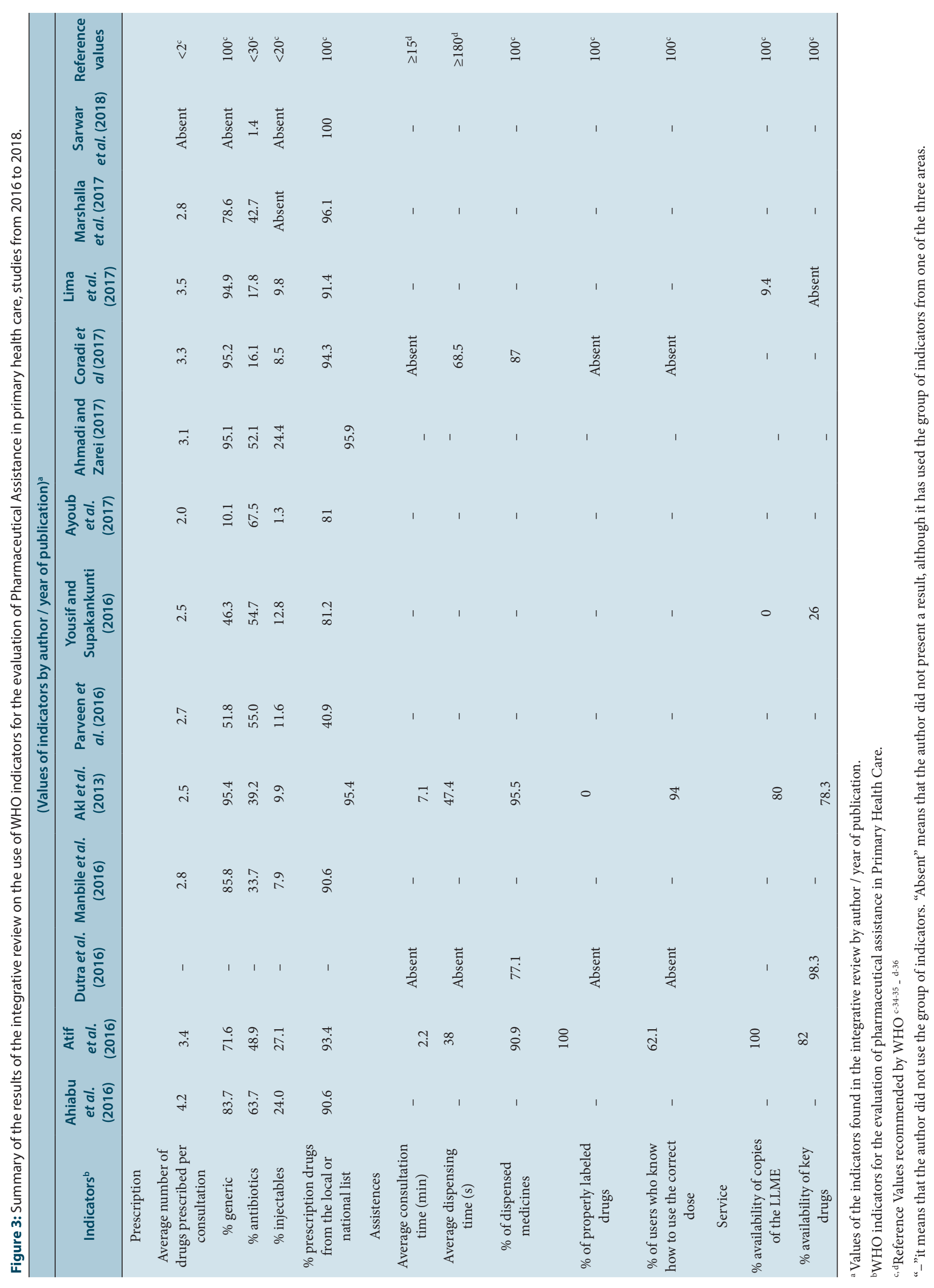


and after 12 months. The authors revealed that this seasonal scarcity in availability was due to problems in the acquisition by the municipality, such as the absence of companies interested in selling to the public sector and delayed deliveries. This result signals the need to improve this indicator, as it directly influences the rational use of medicines. The proportion of patients who spend more than an hour to reach the health unit was only $0.8 \%$, that is, $93.2 \%$ are able to access the health units in less than $30 \mathrm{~min}$. This result suggests that the travel time to the health unit is satisfactory when compared to other studies. ${ }^{17}$ The authors suggested the inclusion of the pharmacist in the health team so that this professional with his knowledge can contribute to better management, both logistically and clinically. ${ }^{9}$

The group of prescription indicators consists of: average number of drugs prescribed per consultation; percentage of drugs prescribed by the generic name; percentage of antibiotics prescribed; percentage of prescribed injectables; percentage of prescription drugs present in the Local Drug List.

The average number of drugs prescribed per consultation was observed that all studies, which used this indicator, were above the value recommended by the World Health Organization $(<2)$, however, three studies showed values close to this reference value. ${ }^{7,18-20}$ what the World Health Organization considers as reasonable up to two drugs per prescription. In a national study involving several states in Brazil, a national average of 2.3 drugs per prescription was found, a result also found in another study conducted in Brasilia / Brazil. ${ }^{21,22}$ A study carried out in the 90s in 12 developing countries found an average between 1.3 to 3.8 prescription drugs. ${ }^{23}$ The number of drugs above the value established by the World Health Organization is considered to be polymedication or polypharmacy, a condition that promotes the irrational use of medications, thus increasing the risks related to their use. The greater number of drugs in a prescription may be related to the unavailability of clinical guidelines and practices, financial incentives to prescribers, lack of continuing education and shortage of therapeutically correct drugs. ${ }^{6}$ In addition, polypharmacy may be related to pressure, by the user population, for the use of the medication that believes that the prescription of more medications will facilitate the cure or relief of their health conditions, due to the belief that the medication will only bring benefits.

In all publications, which used the indicator percentage of drugs prescribed by the generic name was below that recommended by the World Health Organization, which establishes that $100 \%$ of the prescriptions for all drugs must be by the generic denomination (Brazilian Common Denomination or International Common Denomination) to reduce the possibility of errors related to dispensing and allow access to these drugs in health units. The prescription by generic name is an international recommendation and is mandatory in the Unified Health System, a health system established in Brazil, through specific legislation. In addition, the World Health Organization considers it a safety measure for users, because it describes easily accessible information and leads to better communication between health professionals. ${ }^{24-26}$ The discrepancy between thefindings(Figures3,4)inthestudies of theincluded publications may be associated with some reasons, such as the prescribers 'faith in branded products, extensive promotional activities by pharmaceutical companies that influence the prescribers' decisions or the lack of legal binding to prescribe generic drugs. ${ }^{[6]}$ In view of the results, it is very important that strategies are implemented so that the prescribers can know the lists of medications adopted and, thus, can adhere to the use of generic names during consultations in health units. ${ }^{27}$

Of the 20 publications that used the indicator percentage of antibiotics prescribed, only four publications are adequate to the parameters established by the World Health Organization, which recommends that the value be below $30 \%$ for this indicator. ${ }^{8,10,19,28}$ This result leaves an alert for restrictive and educational measures regarding the use of antibiotics. The World Health Organization establishes a standard for the prescription of antibiotics in order to prevent their abuse and, consequently, contribute to the reduction of bacterial resistance and its spread. However, as countries may have different infectious profiles, even with seasonal variation, it is necessary to establish practices such as requalification and continuing education for health professionals regarding the prescription of antibiotics; as well as the establishment of clinical protocols and continuous monitoring so that the oscillation, due to these factors, can be circumvented. ${ }^{5,29}$

Intheindicatorofpercentageofprescribedinjectables, ofthe 17publications, which presented results for this indicator, ten publications meet the parameters established by the World Health Organization $(<20)$, that is, almost half of the publications presented results lower than recommended by the World Organization of health. Several factors can influence the use of injectable drugs such as availability of the drug due to the inclusion in the list of drugs or the lack of availability of the alternative oral therapy, cultural factors with the belief that the effect is more effective. However, the increase in the prescription of injectables is not recommended, due to the increased costs with its acquisition and use, as well as the difficulty in reversing possible reactions that involve its use.

Regarding the indicator percentage of prescription drugs present in the Local List of Medicines, of the 19 publications that used this indicator, only one publication in Pakistan showed 100\% adequacy with that recommended by the World Health Organization. ${ }^{28}$ Another publication from Nigeria had the result (99.1\%) very close to the value recommended by the World Health Organization. ${ }^{30}$ The others were below the recommended level. The incentive to adapt the prescription, based on the adopted drug list, guides the entire chain that involves the drug and its use. Because it is from the list that there is a concentration of all efforts for the inclusion of essential drugs (which have undergone tests, have well-established clinical use and lower costs) appropriate to the local epidemiology, as well as the improvement of the entire logistics chain that involves the acquisition and availability of medicines. ${ }^{31}$

The group of assistance indicators is composed of: average consultation time indicator; average dispensing time; percentage of drugs dispensed; percentage of properly labeled drugs;

In relation to the average consultation time indicator, the six publications that presented results for this indicator. ${ }^{6,18-19,26,32-33}$ showed that all the results found were below the time recommended by the World Health Organization, which establishes a minimum time for an adequate consultation, which must be at least 15 min long. However, the results presented by Brazil and Egypt were $8.6 \mathrm{~min}$ and $7.1 \mathrm{~min}$, respectively, which demonstrates that despite not being within the specified limit, they are less critical than the other evaluated countries that presented values quite critical as in India, Kuwait, Pakistan and Bangladesh, where a variation was found between $1.96 \mathrm{~min}$ and $3.8 \mathrm{~min}$ for consultations. The result of a study carried out on the use of World Health Organization indicators for the rational use of medicines corroborates the results found in low-income and developing countries. ${ }^{29}$ This fact directly influences the quality of patient care, since a time less than $15 \mathrm{~min}$ is not conducive to establishing a relationship of trust between patient / doctor, and, as a consequence, an adequate anamnesis and diagnosis is not performed, thus impairing the holistic care of the patient.

Regarding the average dispensing time, six articles that used this indicator to assess the average time at the time of dispensing, showed that in none of them was there the time necessary to have an adequate dispensation of drugs that include important guidelines regarding the use of the medication by users. ${ }^{6,8,18,26,32,33}$ The best time found in publications was in Bangladesh, where the result was 90 seconds. However, this time is half the amount 
recommended by the World Health Organization $(\geq 15)$ for a quality dispensation for the user. Dispensing time is extremely important, as this is a crucial moment for clarifying doubts and at the same time transmitting necessary and important information for the proper use of medicines by users.

Of the selected publications, eight publications used the indicator percentage of drugs dispensed and none of them presented a result compatible with the value established by the World Health Organization, which recommends that the drugs be dispensed in their entirety, so that users can treat and / or control your morbidities. The value closest to that recommended by the World Health Organization was found in the publication from Kuwait that detected an average of $97.9 \%$ of medicines dispensed. ${ }^{6,8-9,18-19,26,32-33}$ The main reason involved in the low percentage of drugs dispensed may be the inadequate availability of drugs in stock. ${ }^{6}$ Of the selected publications, five publications used the indicator percentage of properly labeled drugs and in only one of them (originally from Pakistan) a positive result was observed in relation to the value established by the World Health Organization, which must be $100 \%$ adequate in relation to this indicator. ${ }^{6,18,26,32-33}$

Of the selected publications, five publications used the indicator percentage of users who know how to use the correct dose of medicines, Egypt (94\%), India (87.1\%), Bangladesh (74.5\%), Pakistan (62.1\%) and Kuwait $(27.6 \%)$, none of these studies was compatible with the value recommended by the World Health Organization, which is $100 \% .{ }^{6,18,26,32-33}$ Users' knowledge of the correct dosage is important to avoid the excessive use of medications and, thus, to prevent possible adverse effects that harm their health. In addition, a good knowledge about the correct dosage provides an overall improvement in health condition. Factors such as low level of education of users and lack of adequate information on the use of medicines, which have been prescribed for them, may be related to the low values found in these indicators.

The group of service indicators is composed of: indicator percentage of availability of the Local Drug List and indicator percentage of availability of key medicines.

About the indicator percentage of availability of the list of drugs (LLME), six publications that used this indicator were found in the review. ${ }^{6,10,14,18,26,32}$ In only one of the studies, carried out in Pakistan, $100 \%$ availability of the copy of the drug list was observed. In general, the result observed in the other studies was unsatisfactory compared to the standard recommended by the World Health Organization (100\%), reaching the total unavailability in two studies carried out in India and Sudan, with 9.4\% availability of list in a study from Brazil. This fact may be related to the lack of incentive to adjust the prescription, based on the list of medications adopted. The unavailability of the medication list precludes the guiding strategy for the rational prescription of medications and, thus, undermines all efforts related to the access and rational use of the medication.

About the indicator percentage of availability of key drugs, six publications that used this indicator were also found in the review. ${ }^{6,914,18,26,33}$ For this indicator, publications also show an unsatisfactory result in relation to that recommended by the World Health Organization (100\%). None of the articles were in agreement with the World Health Organization, but one of the studies carried out in Brazil showed an availability of medicines of $98.3 \%$, a result very close to the recommended value. This indicator reflects the entire organization related to the selection, acquisition and distribution of medicines. And, thus, it becomes an important basis of the process of comprehensive care to the user, where access to medication is an important part of care. In addition, discontinuity in the supply of medications may result in non-adherence to the necessary treatment or purchase of medications in the private sector at the expense of patients. ${ }^{9}$

\section{CONCLUSION}

It was observed in the studies that the group of indicators on the rational use of medicines was the most used, overlapping the other indicators of the World Health Organization (access and quality) applied for monitoring and evaluation in the pharmaceutical sector. In general, the indicators used in the studies included in the review did not show satisfactory results in comparison with the values established by the World Health Organization, which are considered as ideal standards for a good performance in the pharmaceutical sector. This result demonstrates that in several countries, despite the existence of national drug policies, it is still necessary to establish strategies for obtaining more satisfactory results in relation to the rational use of drugs, as well as in relation to prescription, assistance and service in Primary Health Care. The most recurring suggestions found in the studies for obtaining better results regarding the indicators used were continuing education and training of the multidisciplinary team of Primary Health Care regarding the rational use of medicines and the implementation of continuous monitoring so that the expected goals and objectives are achieved. It is important to note that the continuous use of indicators developed by the World Health Organization reveals the current situation in a given location, functioning as a quality thermometer, providing information that will serve as a basis for decision making. Thus, they become guiding elements of the constant search for improving the results related to access to quality medication, as well as its correct use, premises that are established in medication policies.

\section{ACKNOWLEDGEMENT}

Postgraduate Program in Pharmaceutical Sciences at the Federal University of Ceará.

\section{CONFLICT OF INTEREST}

The authors declare no conflict of interest.

\section{ABBREVIATIONS}

PRISMA: Preferred Reporting Items for Systematic Reviews and MetaAnalyses; WHO: World Health Organization; LLME: Local List of Essential Medicines.

\section{REFERENCES}

1. World Health Organization. WHO operational package for assessing, monitoring and evaluating country pharmaceutical situations, guide for coordinators and data collectors. Geneva: WHO. 2007.

2. World Health Organization. How to investigate drug use in health facilities: Selected drug use indicators (WHO/DAPI 93.1). Genebra: WHO. 1993.

3. Lavras C. Atenção Primária à saúde e a organização de Redes Regionais de Atenção à Saúde no Brasil. Saúde Soc. 2011;20(4):867-74. Doi: 10.1590/S010412902011000400005

4. Ahiabu MA, Tersbøl BP, Biritwum R, Bygbjerg IC, Magnussen P. A retrospective audit of antibiotic prescriptions in primary health-care facilities in Eastern Region, Ghana. Health Policy Plan. 2016;31(2):250-8.Doi: 10.1093/heapol/czv048

5. Ahmadi IF, Zarei E. Prescribing patterns of rural family physicians: a study in Kermanshah Province. BMC Public Health. 2017;17(1):908. Doi: 10.1186/ s12889-017-4932-1

6. Atif M, Sarwar MR, Azeem M, Naz M, Amir S, Nazir K. Assessment of core drug use indicators using WHO/INRUD methodology at primary healthcare centers in Bahawalpur, Pakistan. BMC Health Serv Res. 2016;16:684. Doi: 10.1186/s12913-016-1932-2

7. Ayoub SW, Musalam AH, Mahadi AAA. Drug utilization in primary healthcare centers in the Gaza Strip. EMHJ. 2017;23(10):649-56. Doi: 10.26719/2017.23.10.649

8. Coradi CO, Cardoso JS, Groia RCS, Mendes SS, Ceccato MGB, Lima MG. Evaluation of prescriptions and dispensing of medicines in a basic health unit in Belo Horizonte, Minas Gerais, Brazil. Lat Am J Pharm. 2017;36(5):902-6.

9. Dutra RKR, Martins UCM, Lima MG. Availability and Accessibility to Medicines in Primary Health Care in a Brazilian Region. J Young Pharm. 2016;8(3):255-8. Doi: 10.5530/jyp.2016.3.15. 
10. Lima MG, Dutra KR, Martins UCM. Prescribing indicators in primary health care in Belo Horizonte, Brazil: Associated factors. Int J Clin Pharm. 2017;39(4):913-8. Doi: 10.1007/s11096-017-0501-z

11. Mambile G, Kon E, Kydeny BR, Katabalo D, Marwa KJ. Quality of drug prescription in primary health care facilities in Mwanza, north-western Tanzania. J Health Res. 2016;18(4):1-11. Doi: 10.4314/thrb.v18i4.5

12. Mashalla Y, Setlhare V, Massele A, Sepako E, Tiroyakgosi C, Kgatlwane J, et al. Assessment of prescribing practices at the primary healthcare facilities in Botswana with an emphasis on antibiotics: Findings and implications. Int J Clin Pract. 2017;71(12):e13042. Doi: 10.1111/ijcp.13042.

13. Parveen Z, Gupta S, Kumar D, Hussain S. Drug utilization pattern using WHO prescribing, patient care and health facility indicators in a primary and secondary health carefacility. Natl J Physiol Pharm Pharmacol. 2016;6(3):182-6. Doi: 10.5455/njppp.2016.6.23122015108

14. Yousif BM, Supakankunti S. General Practitioners' prescribing patterns at primary healthcare centers in national health insurance, Gezira, Sudan. Drugs Real World Outcomes. 2016;3(3):327-32

15. Song Y, Bian Y, Petzold M, Li L, Yin A. The impact of China's national essential medicine system on improving rational drug use in primary health care facilities: An empirical study in four provinces. BMC Health Serv Res. 2014;14:507 . Doi: 10.1186/s12913-014-0507-3.

16. Moher D, Liberati A, Tetzlaff J, Altman DG. PRISMA Group. Preferred reporting items for systematic reviews and meta-analyses: The PRISMA statement. J Clin Epidemiol. 2009;62(10):1006-12

17. McGrail MR, Humphreys JS, Ward B. Accessing doctors at times of needmeasuring the distance tolerance of rural residents for health-related travel. BMC Health Serv Res. 2015:15:212.

18. Ahmed SM, Islam QS. Availability and rational use of drugs in primary healthcare facilities following the national drug policy of 1982: Is Bangladesh on right track?. J Health Popul Nutr. 2012;30(1):99-108.

19. Menoli PVS, Ivama AM, Juniór LC. Caracterización de los servicios farmacéuticos de atención primaria del Sistema Único de Salud en Londrina, Paraná, Brasil. Rev Panam Salud Publica. 2009:25(3):254-9.

20. Dong $L$, Yanb $H$, Wangc D. Drug prescribing indicators in village health clinics across 10 provinces of Western China. Fam Pract. 2011;28(1):63-7. Doi:10.1093/ fampra/cmq077

21. OPan-Americana da Saúde, Organização Mundial da Saúde, Ministério da Saúde (BR). Avaliação da Assistência Farmacêutica: Estrutura, processo e resultados. Brasília: OPAS/OMS/ Ministério da Saúde. 2005

22. Naves JOS, Silver LD. Avaliação da assistência farmacêutica na atenção primária no Distrito Federal. Rev Saúde Pública. 2005;39(2):223-30.

23. Hogerzeil HV, Ross-Degnan D, Lang RO, Ofori-Adjei D, Santoso B, Chowdhury AK, et al. Field tests for rational drug use in twelve developing countries. Lancet.
1993;342(8884):1408-10.

24. Ministério da Saúde (BR), Agência Nacional de Vigilância Sanitária. Decreto $n^{\circ}$ 3181. Regulamenta a lei $n^{\circ}$ 9.797/1999 que dispõe sobre a vigilância sanitária, estabelece o medicamento genérico, dispõe sobre a utilização de nomes genéricos em produtos farmacêuticos e dá outras providências. Brasília: Ministério da Saúde. 1999.

25. Cruzeta APS, Dourado ACL, Monteiro MTM, Martins RO, Calegario TA Galato D. Fatores associados à compreensão da prescrição médica no Sistema Único de Saúde de um município do Sul do Brasil. Ciênc Saúde Colet. 2013;12(18):3731-7.

26. Akl OA, EIMahalli AA, Elkahky AA, Salem AM. WHO/INRUD drug use indicators at primary healthcare centers in Alexandria, Egypt. J Taibah Univ Med Sci. 2014;9(1):54-64

27. Vooss AT, Diefenthaeler HS. Evaluation of prescription indicators established by the WHO in Getúlio Vargas-RS. Braz J Pharm Sci. 2011;47(2):385-90.

28. Sarwar MR, Saqib A, Iftikhar S, Sadiq T. Antimicrobial use by WHO methodology at primary health care centers: A cross sectional study in Punjab, Pakistan Muhammad Rehan. BMC Infect Dis. 2018;18:492. Doi: 10.1186/s12879-018-3407-z

29. Silva AS, Maciel GA, Wanderley LSL, Wanderley AG. Indicadores do uso de medicamentos na atenção primária de saúde: uma revisão integrativa. Rev Panam Salud Publica. 2017:41:1-12. Doi: 10.26633/ RPSP.2017.132

30. Adisa R, Fakeye TO, Aindero VO. Evaluation of prescription pattern and patients opinion on healthcare practices in selected primary healthcare facilities in Ibadan, South-Western Nigeria. Afr Health Sci. 2015;15(4):1318-29.

31. World Health Organization. The use of essential drugs. Seventh report of WHO Expert Committee (including the revised model list of essential drugs) (WHO Technical Report Series 867). Geneva: WHO. 1997.

32. Awad A, Al-Saffar N. Evaluation of drug use practices at primary healthcare centers of Kuwait. Eur J ClinPharmacol. 2010;66(12):1247-55. Doi: 10.1007/ s00228-010-0872-8

33. Costa A, Bhartiya S, Eltayb A, Nandeswar S, Diwan VK. Patterns of drug use in the public sector primary health centers of Bhopal district. Pharm World Sci. 2008:30(5):584-9. Doi: 10.1007/s11096-008-9215-6.

34. Dumoulin J, Kaddar M, Velasquez G. Guide d'analyseéconomiqueducircuitdum edicament. Geneva: WHO. 2001.

35. World Health Organization. Using indicators to measure country pharmaceutica situations Fact Book on WHO Level I and Level II monitoring indicators. Geneva: WHO. 2006.

36. Bittner MR, Aguilar NG, Menéndez AM. Guia para eldesarrollo de servicio farmaceutico hospitalario. Atención Farmaceutica al Paciente Ambulatorio. Madrid: SEFH. 1997.

Article History: Submission Date : 21-02-2020; Revised Date : 19-04-2020; Acceptance Date : 09-05-2020.

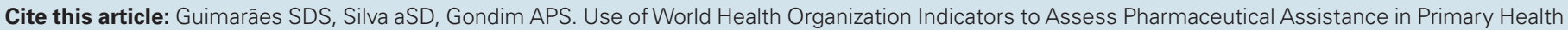
Care: An Integrative Review. J Young Pharm. 2020;12(2):105-12. 